\title{
AN ANALYSIS OF TEAM BASED LEARNING PEDAGOGICAL APPROACH IN INTRODUCTORY ECONOMICS CLASSES
}

\author{
Neetu Kaushik, LAGCC, City University of New York, New York, U.S.A.
}

dx.doi.org/10.18374/JIMS-21-1.2

\begin{abstract}
This paper emphasizes the effectiveness of Team-Based Learning (TBL) as a pedagogical approach in introductory economics classes. TBL is an instructional strategy that can help students master difficult concepts with ease, usually in small group settings, simultaneously developing their critical thinking skills. There is limited research in the area of TBL's effectiveness in economics and social science in general. This study was conducted on two introductory courses, namely, Introduction to Macroeconomics, and Introduction to Microeconomics. Both courses followed regular classroom trainings. Students' grades in individual quizzes were compared with their group quiz results. Further, students' grades in three tests were compared to the grades of a controlled group that did not use the TBL strategy. The results indicated a mixed concoction. While some tests showed an indication of improvement among students under the purview of the TBL approach; other tests showed insignificant difference in performance when compared to a controlled group. In the controlled group, a regular pre-test review was provided.
\end{abstract}

Keywords: Team Based Learning, Group Learning, Flip Learning, Introductory Economics 